\title{
PENENTUAN STRUKTUR TANAH SEBAGAI DASAR UJI KELAYAKAN KEKUATAN BANGUNAN PERUMAHAN DI MUARO JAMBI MENGGUNAKAN METODE GEOLISTRIK KONFIGURASI DIPOLE-DIPOLE
}

\author{
M.Ikhsan $^{1 *}$, Faizar Farid ${ }^{2}$, Samsidar ${ }^{1}$, Linda Handayani ${ }^{1}$ \\ ${ }^{1}$ Program Studi Fisika \\ ${ }^{2}$ Program Studi Kimia \\ Fakultas Sains dan Teknologi \\ Universitas Jambi \\ J1. Jambi-Ma. Bulian KM 15 Mendalo Darat Jambi 36361 \\ *E-mail korespondensi: ikhsan08.mi@gmail.com
}

\begin{abstract}
This research describes the foundation standard in Muaro Jambi. The objective is to determine the subsurface structure as well as to determine the suitable foundation standards for residential buildings in Muaro Jambi. In this study, data collection is divided into 2 residential places, the first in the housing Arza Griya Mandiri and Griya Sungai Duren Indah housing. Each housing will be taking 3 geolistrik data with path length $160 \mathrm{~m}$ and datum point as much as 69 datum. The result of field data obtained in the form of voltage value and current value, this value is inputted into Microsoft Excel software and searched for obstacle value and pa. Datum point value, space electrode, layer, and value pa are combined and input into notepad software to be processed using Res2DINV software. The results show that the foundation has been built almost in accordance with soil structure and foundation of soil obtained from the research. A suitable soil layer to build a foundation is a rocky clay layer where in this study the depth of this layer varies from $1.71 \mathrm{~m}$ to $18.4 \mathrm{~m}$.
\end{abstract}

Keywords: Foundation, soil structure, Res2DINV, geolistrik, dipole-dipole.

\begin{abstract}
ABSTRAK
Penelitian ini memaparkan standar pondasi di Muaro Jambi. Tujuannya untuk menentukan struktur bawah permukaan tanah serta menentukan standar pondasi yang cocok untuk bangunan perumahan di Muaro Jambi. Dalam penelitian ini, pengambilan data dibagi menjadi 2 tempat perumahan, yang pertama di perumahan Arza Griya Mandiri dan perumahan Griya Sungai Duren Indah. Setiap perumahan akan dilakukan pengambilan data geolistrik sebanyak 3 lintasan dengan panjang lintasan $160 \mathrm{~m}$ dan datum point sebanyak 69 datum. Hasil data lapangan yang didapatkan berupa nilai tegangan dan nilai arus, nilai ini diinput kedalam software Microsoft Excel dan dicari nilai hambatan serta pa. Nilai datum point, spasi elektroda, lapisan, dan nilai pa di gabungkan dan di input kedalam software notepad untuk diolah menggunakan software Res2DINV. Hasil yang didapat menunjukkan bahwa pondasi yang telah dibangunan hampir sesuai dengan struktur tanah dan pondasi tanah yang didapat dari hasil penelitian. Lapisan tanah yang cocok untuk dibangun sebuah pondasi adalah lapisan lempung berbatu dimana pada penelitian ini kedalaman lapisan ini bervariasi mulai dari $1.71 \mathrm{~m}$ hingga $18.4 \mathrm{~m}$.
\end{abstract}

Kata kunci: pondasi, struktur tanah, Res2DINV, geolistrik, dipole-dipole.

\section{PENDAHULUAN}

Tanah merupakan benda alam yang terus menerus berubah (dinamis). Hal ini diakibatkan karena pelapukan dan pencucian yang terus menerus sehingga tanah-tanah menjadi semakin tua [1]. Tanah berguna sebagai bahan bangunan pada berbagai macam pekerjaan sipil, selain itu juga berfungsi sebagai pendukung pondasi bangunan [2]. Menurut Hurriyah dan Jannah suatu bangunan yang berdiri di atas tanah akan menimbulkan beban terhadap permukaan bawah tanah, sehingga mengalami tegangan, tergantung beban yang dipikul dan luas pondasi yang digunakan [3]. Hal ini menyebabkan timbulnya perubahan bentuk (deformasi) dan penurunan (settlement) terhadap bangunan yang bersangkutan.

Saat ini, sedang marak pembangunan perumahan sebagai tempat tinggal masyarakat.Daerah yang akan dibuat 
perumahan tersebut awalnya adalah sebuah rawa, tanahnya tidak datar, dan tanah gambut. Sehingga harus ditambah tanah timbunan pada permukaan atasnya yaitu tanah liat, agar bangunan dapat berdiri di tanah tersebut. Penambahan tanah timbunan memungkinkan munculnya masalah baru.Perencanaan pembangunan yang cukup matang sangat diperlukan untuk mencegah timbulnya perubahan bentuk. Oleh karena itu dalam merencanakan pembangunan perlu diketahui kondisi lingkungan seperti struktur bawah permukaan tanah sehingga fenomena kegagalan bangunan tidak terjadi. Menurut Reynold struktur tanah merupakan gumpalangumpalan kecil dari tanah, akibat melekatnya butiran-butiran tanah satu sama lain, dengan tersusunnya fraksi-fraksi tanah primer, terdapat ruang kosong atau pori-pori diantaranya [4]. Dalam menentukan struktur bawah permukaan tanah tersebut dapat digunakan beberapa metode geofisika dan salah satunya adalah metode geolistrik.

Menurut Supriyanto pendugaan geolistrik digunakan untuk eksplorasi yang sifatnya dangkal [5]. Model pendugaan ini menggunakan prinsip perbedaan sifat kelistrikan di dalam batuan dan mineral yaitu resistivitas yang bervariasi. Pada penelitian sebelumnya mengenai struktur tanah oleh Hurriyah dan Jannah, bahwa litologi tanah berupa clay basah memiliki resistivitas $<10$ $\mathrm{m}$, clay padat 10-70 $\mathrm{m}$, limestone 70-200 $\mathrm{m}$, dan andesit $>200 \mathrm{~m}$ [3]. Sedangkan penelitian lain yang dilakukan oleh [6], metode geolistrik digunakan untuk mencari batuan dasar (bedrock), dimana pada penelitian tersebut batuan dasar memiliki kedalaman dengan rentang 7,5-23,5 $\mathrm{m}$ dan nilai resistivitas antara 352-7598 m. Penelitian ini sangat penting dilakukan untuk meneliti struktur lapisan tanah dan standar pondasi yang baik di perumahan yang berada pada Kabupaten Muaro Jambi. Perumahan yang dipilih adalah perumahan Griya Sungai Duren Indah dan Perumahan Arza Griya Mandiri.

\section{METEDOLOGI PENELITIAN}

\section{Tempat dan Waktu}

Penelitian ini dilakukan di 2 tempat yaitu di Perumahan Griya Sungai Duren Indah dengan titik koordinat $1^{0} 35^{\prime} 8.14^{\prime \prime} \mathrm{LS}$ dan $103^{0} 30$ '54.14"BT serta Perumahan Arza Griya Mandiri dengan titik koordinat $1^{0} 36$ '25.42"'LS dan $103^{0} 31^{\prime} 36.04$ ''BT. Waktu penelitian ini tanggal 10 April - 14 April 2018.

\section{Alat dan Bahan Penelitian}

Alat yang digunakan dalam penelitian ini yaitu: seperangkat alat geolistrik resistivitas, 4 buah elektroda, 4 buah proof, 4 gulungan kabel, aki 12 volt, 4 buah kabel penghubung, 3 buah handy talky, multimeter digital, kamera, GPS, meteran, Buku catatan, datasheet, palu, patok.

\section{Akuisisi Data}

Akuisisi data dilakukan dengan menggunakan metode geolistrik konfigurasi dipole-dipole. Menurut Lowrie spasi antar elektroda arus dan antar elektroda potensial pada konfigurasi elektroda dipole-dipole adalah sejauh, dimana jarak antar titik tengah elektroda arus ke titik tengah elektroda potensial sejauh na [7].

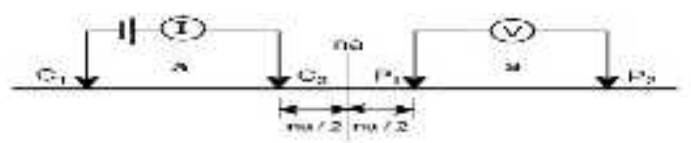

Gambar 1. Spasi elektroda Dipole-Dipole

Proses akuisisi data dilakukan dengan menginjeksikan arus ke bawah permukaan bumi melalui elektroda arus dan akan ditangkap nilai tegangannya melalui elektroda potensial. Nilai akuisisi data yang didapatkan dari lapangan berupa nilai arus dan nilai tegangan yang dicatat pada datasheet. 


\section{Pengolahan Data}

Pengolahan data dilakukan dengan menginput nilai arus dan potensial ke software Ms. Excel dan notepad. Hal ini bertujuan untuk mendapatkan nilai hambatan jenis tanahnya, faktor geometri, dan mendapatkan nilai resisitivitas semu $\left(\rho_{\mathrm{a}}\right)$. Nilai hambatan jenis tanah, faktor geometri, dan resisitivitas semu $\left(\rho_{\mathrm{a}}\right)$ didapatkan menggunakan persamaan berikut:

$$
\begin{aligned}
& R=\frac{V}{I} \\
& k=\pi a(n)(n+1)(n+2) \\
& \rho_{a}=\pi a(n)(n+1)(n+2) \frac{V}{I} \\
& \text { atau } \\
& \rho_{a}=k \times R
\end{aligned}
$$

$R$ adalah hambatan jenis tanahnya ( ), $V$ merupakan nilai potensial $(\mathrm{mV}), I$ merupakan nilai arus $(\mathrm{mA}), k$ merupakan nilai faktor geometri $(\mathrm{m}), \rho_{\mathrm{a}}$ merupakan nilai resistivitas semu ( $\mathrm{m}$ ). Penginputan nilai melalui notepad bertujuan dapat digunakan sebagai data mentah untuk mendapatkan nilai resistivitas sebenarnya melalui software Res2DINV.

\section{Analisis Data}

Hasil pengolahan data akan dianalisis menggunakan software Res2DINV. Res $2 D I N V$ adalah sebuah program komputer yang secara otomatis menentukan model resistivity 2D untuk bawah permukaan dari data hasil survei geolistrik. Menurut Pebriyanto (2016), Program inversi model 2 dimensi pada software Res2DINV digunakan untuk menghitung nilai resistivitas.Nilai resistivitas dari software Res2DINV ditampilkan dalam bentuk gambar bawah permukaan 2D. Hasil gambar tersebut dianalisis dengan nilai resistivitas struktur bawah permukaan tanah dan penentuan pondasi bangunan yang baik.

\section{HASIL DAN PEMBAHASAN}

\section{Interpretasi Data Penelitian di Perumahan Arza Griya Mandiri}

Lintasan 1 merupakan lintasan yang berada tepat di jalan utama penghubung perumahan yang baru dan yang lama dibangun. Titik koordinat dari lintasan ini adalah $01^{0} 36^{\prime} 18.7^{\prime \prime}$ LS dan 103031'35.1" BT sampai $01^{0} 36$ ' 19.9" LS dan 103031'40.2" BT. Pada lintasan 1 Perumahan Arza Griya Mandiri Nilai resistivitas tanah sebesar 54.9 $\mathrm{m}-91.2 \mathrm{~m}$ diinterpretasikan sebagai tanah lanauan pasiran yang berada pada panjang lintasan $15 \mathrm{~m}-65 \mathrm{~m}$ dengan kedalaman 1.71 $\mathrm{m}-6.30 \mathrm{~m}$. Pada nilai resistivitas tanah $152 \mathrm{~m}-252 \mathrm{~m}$ diinterpretasikan sebagai tanah lempung berbatu yang berada pada lintasan $15 \mathrm{~m}-145 \mathrm{~m}$ dengan kedalaman hingga $13.6 \mathrm{~m}$.

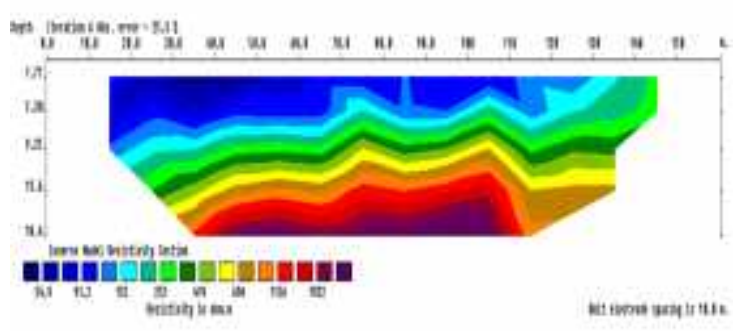

Gambar 2. Hasil Pengolahan Data Res2DINV Perumahan Arza Griya Mandiri Lintasan 1.

Nilai resistivitas sebesar 419 m - 1922 $\mathrm{m}$ diinterpretasikan sebagai tanah batu dasar berisi tanah kering yang berada pada lintasan $15 \mathrm{~m}-145 \mathrm{~m}$ dengan kedalaman mencapai $18.4 \mathrm{~m}$. Hasil interpretasi data lintasan 1 Perumahan Arza Griya Mandiri, Pembangunan pondasi rumah yang disarankan adalah berada pada kedalaman $1.71 \mathrm{~m}$ hingga $9.25 \mathrm{~m}$ dalam bentang $110 \mathrm{~m}-140 \mathrm{~m}$ dan dalam bentangan $15 \mathrm{~m}$ - $100 \mathrm{~m}$ dengan kedalaman di bawah $1.71 \mathrm{~m}$ hingga di atas $13.6 \mathrm{~m}$, karena pada bentangan ini memiliki tanah lempung berbatu sehingga aman untuk dibangun sebuah pondasi rumah. 


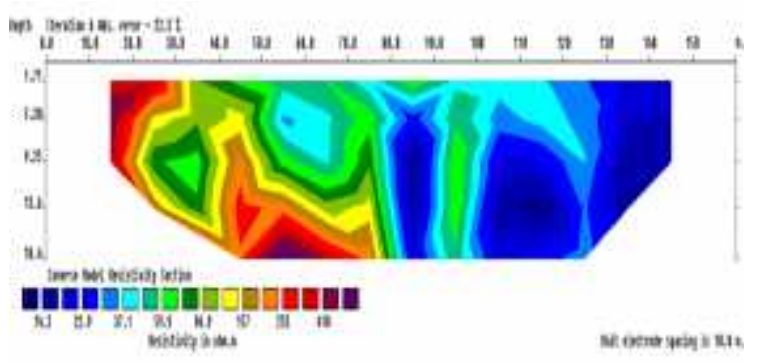

Gambar 3. Hasil Pengolahan Data Res2DINV Perumahan Arza Griya Mandiri Lintasan 2.

Lintasan 2 merupakan lintasan yang berada di perumahan baru Arza Griya Mandiri tepatnya di jalan utama belakang. Titik koordinat dari lintasan ini adalah $01^{0} 36$ ' 17.9 " LS dan $103^{0} 31^{\prime} 39.2$ " BT sampai $01^{0} 36$ ' $15.8^{\prime \prime}$ LS dan $103^{\circ} 31^{\prime} 44.5^{\prime \prime}$ BT. Pada lintasan 2 Perumahan Arza Griya Mandiri, nilai resistivitas tanah sebesar $14.2 \mathrm{~m}-96.9 \mathrm{~m}$ diinterpretasikan sebagai tanah lanauan pasiran yang berada pada panjang lintasan $30 \mathrm{~m}-130$ $m$ dengan kedalaman mencapai 18.4 m.Nilai resistivitas sebesar $157 \quad \mathrm{~m} \quad-253$ mdiinterpretasikan sebagai tanah lempung berbatu yang berada pada lintasan $20 \mathrm{~m}-70$ $\mathrm{m}$ dengan kedalaman mencapai $18.4 \mathrm{~m}$. Nilai resitivitas $410 \mathrm{~m}$ diinterpretasikan sebagai tanah batu dasar berisi tanah kering yang memiliki panjang lintasan mulai dari $15 \mathrm{~m}-$ $25 \mathrm{~m}$ dan 50 - 70 dengan kedalaman mencapai $18.4 \mathrm{~m}$. Hasil interpretasi data lintasan 2 Perumahan Arza Griya Mandiri mempunyai lapisan yang sama dengan lintasan 1 karena letak dan topografi tanahnya sama dan masih sangat berdekatan, hanya saja kedalamannya yang agak berbeda untuk setiap lapisan. Pembangunan pondasi rumah sudah dapat dibangun pada bentangan $30 \mathrm{~m}-75 \mathrm{~m}$ dengan kedalaman mulai dari $1.71 \mathrm{~m}-18.4 \mathrm{~m}$.

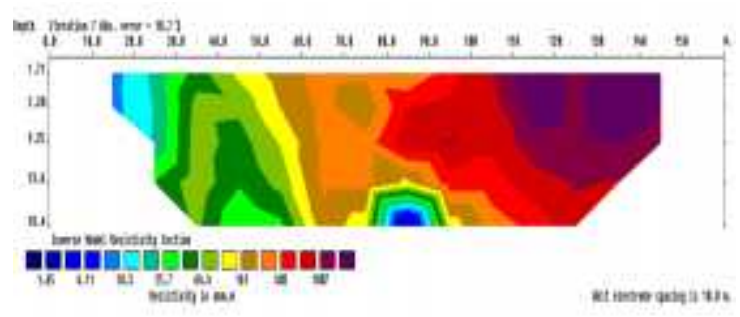

Gambar 4. Hasil Pengolahan Data Res2DINV Perumahan Arza Griya Mandiri Lintasan 3.
Lintasan 3 merupakan lintasan yang berada di perumahan baru Arza Griya Mandiri tepatnya di jalan utama bagian tengah. Titik koordinat dari lintasan ini adalah $01^{0} 36^{\prime} 20.3^{\prime \prime}$ LS dan $103^{0} 31^{\prime} 48.6^{\prime \prime}$ BT sampai $01^{0} 36$ ' $18.8^{\prime \prime}$ LS dan $103^{\circ} 31^{\prime} 42.9^{\prime \prime}$ BT. Pada lintasan 3 Perumahan Arza Griya Mandiri, nilai resistivitas tanah sebesar $1.65 \mathrm{~m}$ diinterpretasikan sebagai Tanah lempung basah dan lembek yang berada pada panjang lintasan $85 \mathrm{~m}$ dengan kedalaman $18.4 \mathrm{~m}$. Nilai resistivitas tanah sebesar $4.11 \mathrm{~m}-10.3 \mathrm{~m}$ diinterpretasikan sebagai Lempung lanauan dan lanauan basah lembek berada pada lintasan $15 \mathrm{~m}$ - $90 \mathrm{~m}$ dengan kedalaman 1.71 $\mathrm{m}-9.25 \mathrm{~m}$. Nilai resistivitas sebesar $25.7 \mathrm{~m}$ - 64.4 mdiinterpretasikan sebagai tanah lanauan pasiran yang berada pada lintasan 25 $\mathrm{m}-60 \mathrm{~m}$ dengan kedalaman $1.71 \mathrm{~m}-13.6 \mathrm{~m}$. Nilai resistivitas sebesar 161 diinterpretasikan sebagai tanah lempung berbatu memiliki panjang lintasan $45 \mathrm{~m}-100 \mathrm{~m}$ memiliki kedalaman mencapai $18.4 \mathrm{~m}$. Nilai resitivitas $403 \mathrm{~m}-1007 \mathrm{~m}$ diinterpretasikan sebagai tanah batu dasar berisi tanah kering yang memiliki panjang lintasan mulai dari $60 \mathrm{~m}-$ $145 \mathrm{~m}$ dengan kedalaman mencapai 18.4 m.Hasil interpretasi data lintasan 3 Perumahan Arza Griya Mandiri mempunyai lapisan dan jenis tanah yang berbeda dengan lintasan 1 dan lintasan 2, karena letak lintasan 3 sendiri yang jauh berbeda letak topografi dan jaraknya dari lintasan 1 dan lintasan 2. Pada lintasan 3 pembangunan pondasi sudah bisa dilakukan mulai dari kedalaman $1.71 \mathrm{~m}$ hingga $18.1 \mathrm{~m}$, pada bentangan $35 \mathrm{~m}-60 \mathrm{~m}$ akan tetapi pada bentangan ini mempunyai resiko terjadi penurunan tanah langsung karena lapisan ini mempunyai lapisan tanah lanauan pasiran yang sedikit sulit untuk menahan pondasi.

\section{Interpretasi Data Penelitian di Perumahan Griya Sungai Duren Indah}

Lintasan 1 merupakan lintasan yang berada di perumahan Griya Sungai Duren Indah tepatnya di jalan utama bagian belakang perumahan. Titik koordinat dari lintasan ini 
adalah $01^{0} 35$ '27.6" LS dan $103^{0} 30$ '16.5" BT sampai $01^{0} 35^{\prime} 22.6^{\prime \prime} \mathrm{LS}$ dan $103^{0} 30^{\prime} 17.0^{\prime \prime} \mathrm{BT}$.

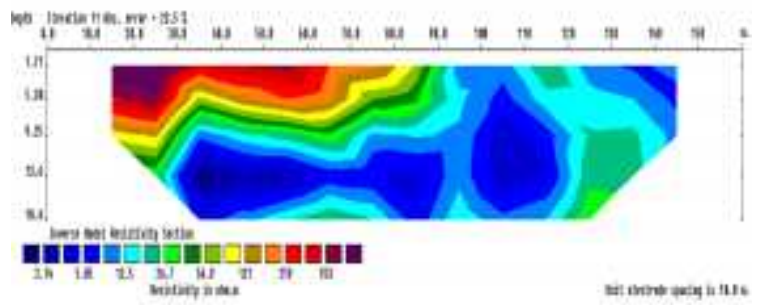

Gambar 5. Hasil Pengolahan Data Res2DINV Perumahan Griya Sungai Duren Indah Lintasan 1.

Pada lintasan 1 perumahan Griya Sungai Duren Indah, nilai resistivitas tanah sebesar $2.74 \mathrm{~m}$ diinterpretasikan sebagai Tanah lempung basah dan lembek yang berada pada panjang lintasan $35 \mathrm{~m}-55 \mathrm{~m}$ dengan kedalaman dibawah $9.25 \mathrm{~m}$ dan diatas $13.6 \mathrm{~m}$. Nilai resistivitas tanah sebesar $5.85 \mathrm{~m}-12.5$ mdiinterpretasikan sebagai Lempung lanauan dan lanauan basah lembek berada pada lintasan $25 \mathrm{~m}-140 \mathrm{~m}$ dengan kedalaman $9.25 \mathrm{~m}$ - $18.4 \mathrm{~m}$. Nilai resistivitas sebesar $26.7 \mathrm{~m}-121 \mathrm{~m}$ diinterpretasikan sebagai tanah lanauan pasiran yang berada pada lintasan $15 \mathrm{~m}$ - $90 \mathrm{~m}$ dengan kedalaman 1.71 $\mathrm{m}-9.25 \mathrm{~m}$. Nilai resitivitas $259 \mathrm{~m}$ diinterpretasikan sebagai tanah lempung berbatu yang memiliki panjang lintasan mulai dari $15 \mathrm{~m}-70 \mathrm{~m}$ dengan kedalaman $1.71 \mathrm{~m}-$ $5.30 \mathrm{~m}$. Nilai resitivitas $553 \mathrm{~m}$ diinterpretasikan sebagai tanah batu dasar berisi tanah kering yang memiliki panjang lintasan mulai dari $15 \mathrm{~m}-60 \mathrm{~m}$ dengan kedalaman mencapai $5.30 \mathrm{~m}$.Hasil interpretasi data lintasan 1 perumahan Griya Sungai Duren Indah, untuk pembangunan konstruksi ringan sudah dapat dilakukan pada kedalaman 1.71 $\mathrm{m}$, tetapi untuk membuat bangunan rumah pada bentangan antara $85 \mathrm{~m}-145 \mathrm{~m}$ mempunyai resiko terjadi penurunan tanah langsung karena lapisan ini mempunyai lapisan tanah lanauan pasiran. Pembangunan pondasi rumah yang disarankan adalah berada pada kedalaman $1.71 \mathrm{~m}$ hingga $9.25 \mathrm{~m}$ dalam bentang $65 \mathrm{~m}-80 \mathrm{~m}$, karena pada bentangan ini memiliki tanah lempung berbatu sehingga aman untuk dibangun sebuah pondasi rumah.

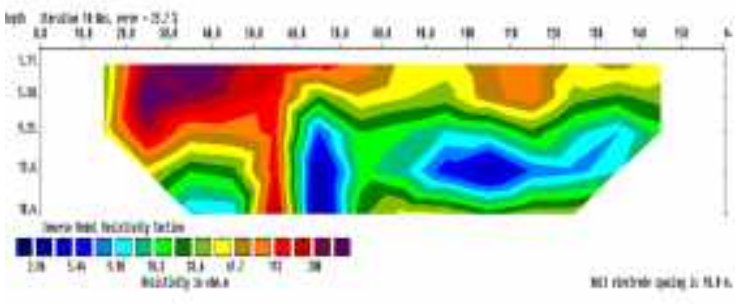

Gambar 5. Hasil Pengolahan Data Res2DINV Perumahan Griya Sungai Duren Indah Lintasan 2.

Lintasan 2 merupakan lintasan yang berada di perumahan Griya Sungai Duren Indah tepatnya di jalan utama bagian tengah perumahan. Titik koordinat dari lintasan ini adalah $01^{0} 35$ '22.7" LS dan $103^{0} 30^{\prime} 14.5$ " BT sampai $01^{0} 35$ '27.9" LS dan $103^{0} 30^{\prime} 14.4^{\prime \prime}$ BT. Pada lintasan 2 perumahan Griya Sungai Duren Indah, nilai resistivitas tanah sebesar $2.96 \mathrm{~m}$ diinterpretasikan sebagai Tanah lempung basah dan lembek yang berada pada panjang lintasan $35 \mathrm{~m}-55 \mathrm{~m}$ dengan kedalaman dibawah $9.25 \mathrm{~m}$ dan diatas $13.6 \mathrm{~m}$. Nilai resistivitas tanah sebesar $5.44 \quad \mathrm{~m}-9.98$ $\mathrm{m}$ diinterpretasikan sebagai Lempung lanauan dan lanauan basah lembek berada pada lintasan $30 \mathrm{~m}-140 \mathrm{~m}$ dengan kedalaman mencapai. Nilai resistivitas sebesar $18.3 \mathrm{~m}-$ $113 \mathrm{~m}$ diinterpretasikan sebagai tanah lanauan pasiran yang berada pada lintasan 25 $\mathrm{m}-90 \mathrm{~m}$ dengan kedalaman $1.71 \mathrm{~m}-13.6 \mathrm{~m}$. Nilai resitivitas $208 \mathrm{~m}$ diinterpretasikan sebagai tanah lempung berbatu yang memiliki panjang lintasan mulai dari $25 \mathrm{~m}-50 \mathrm{~m}$ dengan kedalaman mencapai 9.25 m.Hasil interpretasi data geolistrik lintasan 2 perumahan Griya Sungai Duren Indah mempunyai lapisan yang berbeda dengan lintasan 1 karena Pembangunan pondasi rumah yang disarankan menurut hasil interpretasi geolistrik adalah pada bentangan $20 \mathrm{~m}-55 \mathrm{~m}$ karena pada bentangan $20 \mathrm{~m}-55 \mathrm{~m}$ dengan kedalaman $1.71 \mathrm{~m}$ sudah ada tanah lempung berbatu yang mana lapisan tanah ini sangat bagus dan aman jika dibangun pondasi rumah biasa hingga rumah bertingkat 3 . 


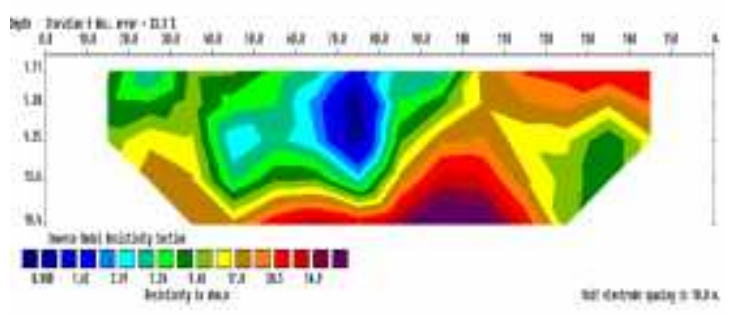

Gambar 6. Hasil Pengolahan Data Res2DINV Perumahan Griya Sungai Duren Indah Lintasan 3.

Lintasan 3 merupakan lintasan yang berada di perumahan Griya Sungai Duren Indah tepatnya di jalan utama bagian depan perumahan. Titik koordinat dari lintasan ini adalah $01^{0} 35^{\prime} 22.4^{\prime \prime}$ LS dan $103^{0} 30^{\prime} 13.9$ " BT sampai $01^{0} 35^{\prime} 28.3^{\prime \prime}$ LS dan $103^{0} 30^{\prime} 13.4$ " BT. Pada lintasan 3 perumahan Griya Sungai Duren Indah, Nilai resistivitas tanah sebesar $0.900 \mathrm{~m}$ diinterpretasikan sebagai Tanah lempung basah dan lembek yang berada pada panjang lintasan $35 \mathrm{~m}-55 \mathrm{~m}$ dengan kedalaman dibawah $9.25 \mathrm{~m}$ dan diatas $13.6 \mathrm{~m}$. Nilai resistivitas tanah sebesar $1.62 \mathrm{~m}-2.91$

$\mathrm{m}$ diinterpretasikan sebagai tanah lempung basah dan lembek berada pada lintasan $30 \mathrm{~m}-$ $90 \mathrm{~m}$ dengan kedalaman $9.25 \mathrm{~m}-18.4 \mathrm{~m}$. Nilai resistivitas sebesar $5.24 \mathrm{~m}-9.43 \mathrm{~m}$ diinterpretasikan sebagai Lempung lanauan dan lanauan basah lembek yang berada pada lintasan $15 \mathrm{~m}$ - $90 \mathrm{~m}$ dengan kedalaman 1.71 $\mathrm{m}-13.6 \mathrm{~m}$. Nilai resistivitas sebesar $17.0 \mathrm{~m}$ $54.9 \mathrm{~m}$ diinterpretasikan sebagai tanah lanauan pasiran memiliki panjang lintasan 15 m - 80 m memiliki kedalaman 1.71 m - 9.25 m.Hasil interpretasi data geolistrik lintasan 3 perumahan Griya Sungai Duren Indah mempunyai lapisan yang berbeda dengan lintasan 1 dan lintasan 2 hal ini dikarena lapisan bawah permukaan tidak menunjukkan adanya batuan dasar berisi tanah kering dan juga tidak ada lapisan yang menunjukkan tanah lempung berbatu sehingga untuk membuat konstruksi berat haruslah dilakukan penelitian lebih lanjut yang bisa melihat lebih dari $18.4 \mathrm{~m}$ di bawah permukaan.

\section{Interpretasi Standar Pondasi}

Menurut peta geologi Provinsi Jambi, daerah mendalo merupakan daerah yang memiliki material atau lapisan bawah permukaannya berupa bongkah, kerikil, pasir, lanau, lumpur dan lempung. Hasil interpretasi dari Perumahan Arza Griya Mandiri dan Griya Sungai Duren Indah bisa dikatakan hasil yang didapat sama dengan peta geologi tersebut. Berdasarkan informasi yang didapatkan dari Ketua Rt 15, bahwasanya pada Perumahan Arza Griya Mandiri kedalaman pondasi yang dibangun hampir mencapai $1 \mathrm{~m}$ di bawah permukaan tanah. Melihat dari hasil interpretasi yang telah dilakukan di atas bahwasanya untuk kelayakan pondasi yang telah dibangun dan kedalaman pondasi yang disarankan melalui penelitian sudah memiliki kesamaan. Berdasarkan [8], pembangunan sebuah konstruksi ringan seperti rumah lantai 1, 2 dan 3 sudah dapat dilakukan pada lapisan tanah lempung. Tanah lempung merupakan tanah yang sifatnya bisa lunak dan bisa kering.Lintasan yang harus dipertimbangkan adalah pada lintasan 3, dimana pada lintasan ini saat pengambilan data lapangan kondisi tanah sedang tergenang oleh air rawa.

Lain halnya dengan perumahan Griya Sungai Duren Indah, dimana menurut petugas kantor pemasaran bahwasanya pembangunan pondasi di perumahan ini berada tepat $1 \mathrm{~m}$ di bawah permukaan tanah. Pembangunan pondasi dan interpretasi data hasil penelitian yang telah dilakukan sudah memiliki kesamaan. Dimana setiap lintasan memiliki lapisan yang berbeda-beda namun pada lintasan 1 dan lintasan 2 masih bisa dilakukan pembangunan pondasi rumah dengan kedalaman diatas $1.71 \mathrm{~m}$ ataupun di bawah $1.71 \mathrm{~m}$. Akan tetapi pada lintasan 3 harus dipertimbangakan kembali jika ingin dibangun sebuah pondasi rumah, mengingat pada lintasan ke 3 ini lapisan tanah yang ada dibawah permukaan menunujukkan bahwa tidak adanya tanah lempung berbatu hingga kedalaman 18.4, sehingga untuk pembangunan sendiri harus diperhitungkan kembali megingat 
takut terjadi hal yang tidak diinginkan seperti penurunan tanah dan retaknya bagian dari pondasi ataupun dinding rumah.

\section{KESIMPULAN}

Setelah dilakukan pengambilan data lapangan dan memasukkan nilai resistivitas semua $\left(\rho_{\mathrm{a}}\right)$ ke dalam software maka didapatkan nilai resistivitas. Pada Perumahan Arza Griya Mandiri menunjukkan struktur lapisan bawah permukaan tanahnya terdiri atas tanah lempung basah dan lembek, tanah lempung lanauan dan lanauan basah lembek, tanah lanauan pasiran, tanah lempung berbatu, dan batu dasar berisi tanah kering. Sedangkan pada Perumahan Griya Sungai Duren Indah struktur bawah permukaan tanahnya antara lintasan 1 dan lintasan 2 hampir sama dengan Perumahan Arza Griya Mandiri. Sedangkan pada lintas terakhir struktur lapisan tanahnnya tidak mengandung tanah lempung berbatu, dan batu dasar berisi tanah kering. Berdasarkan [8], standar pondasi yang baik pada Perumahan Arza Griya Mandiri untuk pembangunan sebuah pondasi sudah bisa dibangun pada kedalaman $1.71 \mathrm{~m}$. Sedangkan untuk perumahan Griya Sungai Duren Indah hampir sama dengan Perumahan Arza Griya Mandiri dimana pada lintasan 1 dan 2 perumahan ini sudah dapat dibangun sebuah pondasi pada kedalaman $1.71 \mathrm{~m}$ juga. Namun pada lintasan 3 agar tidak di bangun sebuah pondasi rumah karena pada lintasan ini struktur lapisan bawah permukaan tanahnya menunjukkan tidak adanya tanah lempung berbatu yang ideal untuk dibangun sebuah pondasi rumah.

\section{REFERENSI}

1. Hardjowigeno, S. (2007). Ilmu Tanah, Edisi Baru. Akademika Pressindo: Jakarta.
2. Hardiyatmo, H. C. (2002). Mekanika Tanah I, Edisi 3. Gadjah Mada University Press: Yogyakarta.

3. Hurriyah \& Jannah, R. (20150. Analisis Struktur Lapisan Bawah Permukaan Menggunakan Metode Geolistrik (Studi Kasus Pada Kampus III IAIN Imam Bonjol Padang di Sungai Bangek Kecamatan Koto Tangah). Jurnal Spasial, 28-39.

4. Reynolds, J. M. (1997). An Introduction to Applied and Enviromental Geophysics. Jhon Wiley \& Sons Ltd: Chichester.

5. Supriyanto. (2012). Interpretasi Pola Sebaran Air tanah di Kawasan Perumahan Tepian Samarinda dengan Metode Geolistrik Tahanan Jenis. Mulawarman Scientifle, 11(2), 163-174.

6. Bavitra, Akmam, \& Amir, H. (2015). Estimasi Kedalaman Batuan Dasar Menggunakan Metode Inversi Robust 2- D Data Geolistrik Tahanan Jenis Konfigurasi Dipole-Dipole Di Bukit Apit Puhun Kecamatan Guguk Panjang Kota Bukit Tinggi. Pillar of Physics, (6): 1-8.

7. Lowrie, W. (2007). Fundamentals of Geophysics. Cambridge University Press: New York.

8. Jumantoro, R. (2015). Analisis Bawah Permukaan Tanah Kerikil Pasir Lempung dan Lanau. Civil Engineering. 